\title{
Integrated and Simultaneous Model of Power Expansion Planning with Distributed Generation
}

\author{
Rahmat A. Al Hasibi ${ }^{1}$, Sasongko P. Hadi ${ }^{2}$, Sarjiya $^{3}$
}

\begin{abstract}
This study proposes a model based on mixed-integer linear programming (MILP) for the integrated expansion planning of generation and transmission systems with the implementation of distributed generation (DG). Most DG planning takes place after generation and transmission planning has been conducted. This model can be used to include DG potential simultaneously with generation and transmission expansion. $D G$ is modelled as a negative load therefore DG is treated as a non-dispatchable unit of power generation. The objective of the model is to minimize overall cost including the investment cost of the generation units, DG units, and transmission lines, and the operating cost of the generation and DG units. The proposed model is staticdeterministic model in the form of MILP. The model was evaluated using the 6-bus Garver's test. To prove the effectiveness of the model, it was evaluated using the IEEE 46 Bus Test. The results show that due to the impact of DG on power system expansion planning, the overall cost was reduced. The simulation results also show that a different optimal network configuration can be achieved by DG implementation in expansion planning. Copyright $\odot 2018$ The Authors.

Published by Praise Worthy Prize S.r.l. This article is open access published under the CC BY-NC-ND license (http://creativecommons.org/licenses/by-nc-nd/3.0/).
\end{abstract}

Keywords: Integrated Expansion Planning, Generation Expansion, Transmission Expansion, Distributed Generation, Mixed Integer Linear Programming

\section{Nomenclature}

\section{Indices}

$i, j$

$n g$

nc

$g t$

$q$

$o$

Sets

$\Omega_{o}$

$\Omega$

Parameters

$B_{i j}$

$U_{i, j}^{E L}$

$F L_{i j}^{M a x}$

$I L_{i j}$

$E P G_{i, g t}^{M a x}$

$N P G_{g t, q}^{o p t}$

Bus each bus

Generator technology generator technology

Demand block bus $i, j[\mathrm{~S}]$ line connected bus $i, j$ [\$]
Number of generators over plants on

Number of circuit over two buses

Generator option capacity for each

Existing transmission lines

Prospective transmission lines

Transmission line susceptance connected

Circuit number of existing transmission

Maximum flow capacity of transmission line connected bus $i, j$ [MW]

Investment line of transmission line

Maximum capacity of existing generation unit installed in bus $i$ [MW]

Capacity option of new generating units each generator technology $g t$ for option $q$ [MW]

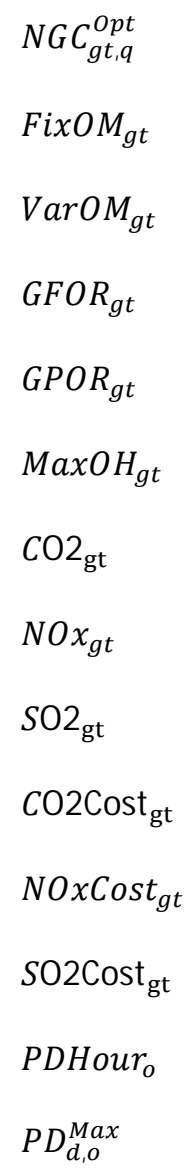

Cost of new generating units each generator technology gt for option $q$ [\$] Fixed O\&M cost for each generator technology $g t$ [\$]

Variable O\&M cost for each generator technology $g t[\$]$

Forced outage rate for each generator technology $g t[\%]$

Planned outage rate for each generator technology $g t[\%]$

Maximum operating hours of generator technology $g t$

$\mathrm{CO}_{2}$ emission factor for each generator technology $g t$ [Ton/kWh]

$\mathrm{NO}_{\mathrm{x}}$ emission factor for each generator technology $g t$ [Ton/kWh]

$\mathrm{SO}_{2}$ emission factor for each generator technology gt [Ton/kWh]

Cost of $\mathrm{CO}_{2}$ emission factor for each generator technology $g t$ [\$/Ton]

Cost of $\mathrm{NO}_{\mathrm{x}}$ emission factor for each generator technology $g t$ [\$/Ton]

Cost of $\mathrm{SO}_{2}$ emission factor for each generator technology $g t$ [\$/Ton]

Demand level duration for demand block $o$ [hours]

Maximum demand level in each demand 


\begin{tabular}{|c|c|}
\hline & bus $d$ for demand block $o$ [MW] \\
\hline$M R M$ & Maximum reserve margin [\%] \\
\hline Variables & \\
\hline$P G_{i, o}^{E}$ & $\begin{array}{l}\text { Electricity production of installed } \\
\text { generation units }[\mathrm{MWh}]\end{array}$ \\
\hline $\operatorname{Bin}_{i, g t, n g, q}^{G}$ & $\begin{array}{l}\text { Binary decision variable of new } \\
\text { generating units }\{0,1\}\end{array}$ \\
\hline$N P G_{i, g t, n g}^{M a x}$ & $\begin{array}{l}\text { Maximum capacity of new generating } \\
\text { units }[\mathrm{MW}]\end{array}$ \\
\hline$P G_{i, g t, o}^{N}$ & $\begin{array}{l}\text { Electricity production of new generating } \\
\text { units [MWh] }\end{array}$ \\
\hline $\operatorname{Bin}_{i, d g t, n d g, d g q}^{D G}$ & $\begin{array}{l}q \text { Binary decision variable of new DG units } \\
\{0,1\}\end{array}$ \\
\hline$W_{i, g t, n g}^{G}$ & $\begin{array}{l}\text { Electricity production by each generating } \\
\text { unit [MWh] }\end{array}$ \\
\hline$W_{i, g t, n g}^{D G}$ & $\begin{array}{l}\text { Electricity production by each DG unit } \\
{[\mathrm{MWh}]}\end{array}$ \\
\hline$N D G_{i, g t, n g}^{\operatorname{Max}}$ & $\begin{array}{l}\text { Maximum capacity of new DG units } \\
{[\mathrm{MW}]}\end{array}$ \\
\hline$N P D G_{i, g t, o}$ & $\begin{array}{l}\text { Electricity production of new DG units } \\
{[\mathrm{MWh}]}\end{array}$ \\
\hline$P L_{i j, o}$ & Line power flow [MW] \\
\hline $\operatorname{Bin}_{i j, n c}^{L}$ & $\begin{array}{l}\text { Binary decision variable of new } \\
\text { transmission line }\{0,1\}\end{array}$ \\
\hline$\theta_{i, o}$ & Bus angle [rad] \\
\hline
\end{tabular}

\section{Introduction}

Electricity demand continues to increase relative to the growth in the population and economic activity. Ensuring a reliable supply of electricity to meet demand is the main task of generation companies (GENCOs). In general, generation expansion planning (GEP) aims to determine the optimal capacity of power plants in order to satisfy the system load. GEP is undertaken prior to transmission expansion planning (TEP). GEP and TEP also can be undertaken simultaneously.

The coordination of GEP and EP is based on a heuristic market-based simulation model in [1]. This study proposes decision of the investment based on desirable location generated by individual decisions of stakeholder of autonomous market. This model was constrained by limited information shared by the market players. The proposed model in this study results expansion mechanism on generation and transmission capacity based on market that enable competition to follow market need. The simultaneous planning for generation and transmission capacity based on reliability was done in [2] based on the DC model of load flow. This DC load flow was used to indicate the constraint of the transmission flow that eliminates the disconnected bus problem. A reliability assessment was undertaken at the hierarchical level (HL) II. The result of this model showed economic level of reliability for a given system with minimum investment cost. The coordination of GEP and TEP was also undertaken with fuel transport being a constraint in the model proposed in [3]. In addition to reducing the capital cost of the new generation unit and adding a new transmission line, another constraint is the fuel cost, including the cost of transporting the fuel to the generating unit locations. Fuel availability was also treated as a constraint in this model. The co-optimization of the GEP and TEP model based on a micro-grid was proposed in [4]. As well as the capital cost of the addition of a new generation unit and transmission line, this model also included the investment and operating cost of the local micro-grid and the cost of expected unserved energy. The reliability of the system was taken into consideration by including the cost of unserved energy which reflects the cost of load shedding. This model of co-optimization was divided into an expansion problem and a yearly reliability sub-problem. The optimal solution was resulted by the examination planning problems with addition of system reliability as an objective of sub-problem. A static model of simultaneous GEP and TEP was proposed with three-level mixed integer linear programming (MILP) with a case study on the power system in Chile in [5]. In the model, the lowest level represented market-based equilibrium, the intermediate level represented equilibrium in generation capacity expansion, and the upper level represented transmission line expansion based on the expansion of generation capacity. A probabilistic approach to the integration of GEP and TEP was proposed in [6]. This model also considered the criteria of power system reliability. Reliability criteria was represented by the random outage of a generator and transmission line known as the chronological forced-outage rate (FOR). The cost consideration of the model included capital and operation cost along with the cost of expected energy not supplied (EENS). A dynamic model of coordination of GEP and TEP was proposed in the form of mixed integer nonlinear programming (MINLP) [7]. Bender's decomposition method was used to transform MINLP into MILP as a main problem and linear programming (LP) as a sub-main problem. The model also investigated the system reliability at HL II. Another form of dynamic model is the multi-period integrated framework that was developed in [8] for GEP and TEP and natural gas grid expansion planning. The objectives of this model were to minimize the total capital cost and operation cost of electrical power generation as well as the natural gas grid. The result of the model were generation requirement with location and capacity, transmission line requirement with type and lines termination, and natural gas grid requirement to provide newly built power plant and natural gas need. A coordinated generation and transmission expansion planning model based on the probabilistic approach was proposed in [9] as a multiobjective model using non-boundary intersection. This model instantaneously minimizes the overall cost of planning and fuel, externality cost in term of $\mathrm{SO}_{2}$ and NOx emission and fuel price changes while the reliability of the power system is maximized. A Pareto-optimal solution was achieved by incorporating the non-boundary intersection method. 
Distributed generation (DG) is seemly a more attractive option in the planning and operation of power systems. Even so, a model which implements DG focuses on the distribution network. The impact of DG implementation on a distribution network can be viewed from several perspectives, such as improving reliability [10], [11], reducing distribution network losses [12]-[14], incentive cost impact [15], and improving voltage stability [16], [17]. In relation to transmission expansion planning, several models which implement DG have been proposed. The impact of DG implementation on the TEP model in reducing cost can be seen in [18]. The results of this model show that DG may reduce the capital cost in transmission expansion planning. However, the impact of DG implementation is significantly affected by many aspects, such as DG location, network topology, and technical constraints in the power system. A TEP model with DG implementation was also proposed with a multi-objective optimization model in [19]. This model comprised several uncertain variables which resulted in flexible decision-making in relation to in transmission capacity expansion. The uncertain variables in this model were generation expansion, system load, and other markets variable. A combined model of GEP and TEP with intermittent renewable energy sources was also proposed in [20]. Coordination model of GEP and TEP with the implementation of DG was proposed in [21]. This model treated the optimization model of DG as separated model from the main model of GEP and TEP. The first step was determination of optimal generation planning. The optimal of DG capacity was earned by separated optimization model. In combined model of GEP and TEP, DG capacity was used to adjust network demand. There is also no binary decision variable in this model.

The main contributions of this paper are:

1. a model is proposed which includes the simultaneous determination of generation capacity and transmission line adequacy, and

2. distributed generation is added in the proposed model as an integrated objective and constraint function which is different from the model previously proposed in [21]. In this model, GEP and TEP are undertaken in the one process of optimization.

\section{Problem Statement}

The optimal design and planning of an interconnected power system deals with the optimization of power generation and transmission capacity expansion to meet the given electrical load. Expansion planning can be divided into generation expansion planning (GEP) and transmission expansion planning (TEP). Expansion planning involves a single bus or a multi-bus approach. The single bus approach assumes the transmission network is never overloaded for a projected demand whereas the multi-bus approach is limited by the capacity of the transmission network. Usually, GEP is undertaken prior to TEP, hence the outcomes of GEP will be used as input for TEP. The goal of TEP is to minimize network expansion considering GEP and projected demand.

The model proposed in this paper is developed based on the integration of GEP and TEP. Using this model, generation and transmission capacity expansion planning can be done simultaneously. This model is well suited for power systems that cover a very large area [22]. On the other hand, DG plays an important role in modern power systems. Consideration should also be given to DG in the expansion planning of power systems. Therefore, the proposed model will also include DG as a component in expansion planning. The impact of DG implementation will be analyzed in terms of the reduction in the overall system cost and deferral of network configuration.

\section{Problem Formulation}

The integrated model of GEP and TEP is written as a G-TEP model in the form of a mathematical programming problem. This problem comprises binary variables that denote whether the transmission lines are built or not and other binary variables for generating and DG units. The model will be developed as mixed integer nonlinear programming (MINLP) model where the product of binary variables and continuous variables appear in TEP formulation. To reduce the computation time, the developed MINLP model will be converted to a MILP model by the linearization of the nonlinear constraint.

\section{III.1. Load Duration Curve}

The operational condition of a power system is represented by the load duration curve (LDC). LDC describes the load level change over time which is used to determine the level of generating unit production. In the view of expansion planning, LDC consists of load level information for each hour in a year.

From the view of expansion planning, linear approximation is used to produce practical LDC. Linear LDC is shown in Fig. 1.

\section{III.2. Objective Function}

The objective function of the G-TEP problem is to minimize the overall expansion cost. Considering the static-deterministic model, the objective function of the G-TEP problem is expressed as shown in equation (1). The objective function in (1) consists of four part which are investment cost of newly built generating units $N G^{i n v}$, operation cost of installed and newly built generating units $G^{O M}$, investment cost of an added transmission line $N L^{i n v}$, and externality cost of electricity production by the installed and new generating units $G^{E C}$. Each part of the objective function is defined in equations (2) to (5) respectively:

$$
\min \left(N G^{i n v}+G^{O M}+N L^{i n v}+G^{E C}\right)
$$




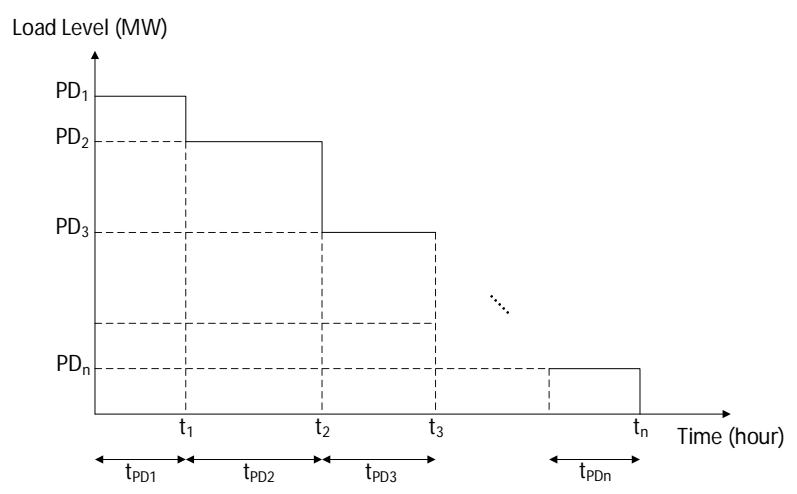

Fig. 1. Linear LDC of electrical power system

$$
\begin{aligned}
& N G^{i n v}=\sum_{i} \sum_{g t} \sum_{n g} \sum_{q=1}^{q} N G C_{g t, q}^{o p t} B i n_{i, g t, n g, q}^{G} \\
& G^{\text {OM }}=\sum_{o} \text { PDHour }_{o} \sum_{i} \sum_{g t} \operatorname{VarOM}_{g t}\left(P G_{i, o}^{E}\right. \\
& \left.+P G_{i, g t, o}^{N}\right) \\
& N L^{i n v}=\sum_{i} \sum_{j} \sum_{n c} I L_{i j} \operatorname{Bin}_{i, j, n c}^{L} \\
& G^{E C}=\sum_{o} \text { PDHour }_{o} \sum_{i} \sum_{n c}\left(C \mathrm{O}{ }_{\mathrm{gt}} \text { CO } 2 \text { Cost } \mathrm{gt}\right. \\
& +\mathrm{NOX}_{\mathrm{gt}} N O \mathrm{XCOSt}_{\mathrm{gt}} \\
& \left.+S O 2_{\mathrm{gt}} \mathrm{SO} 2 \text { Cost }_{\mathrm{gt}}\right)\left(P G_{i, o}^{E}+P G_{i, o}^{N}\right)
\end{aligned}
$$

\section{III.3. DC Load Flow}

Power flow in the G-TEP model is used as a constraint. The power flow equation is used to determine the power balance in every node or bus before and following expansion planning. In this model, the DC power flow will be implemented. The state of each bus before expansion, power flow $\mathrm{n}$ is calculated by equation (6). $P_{G}^{0}$ and $P_{D}^{0}$ are the active power of generating unit and peak load of demand. $B^{0}$ and $\theta^{0}$ are the line susceptance matrix and voltage angle vector at peak load before expansion. The variable after expansion can be stated as $P_{G}^{t}, P_{D}^{t}$, vector $\theta^{t}$, and matrix $B^{t}$. The power balance in each bus after expansion is calculated using equation (7). The difference between each variable before and after expansion is stated in equations (8)-(11). $\Delta P_{G}$ represents the added generation unit. Demand growth is represented by $\Delta P_{D}$. The additional line which is needed in after expansion is represented by $\Delta B$. The voltage angle deviation before and after expansion is represented by $\Delta \theta$ :

$$
\begin{gathered}
P_{G}^{0}-P_{D}^{0}=B^{0} \cdot \theta^{0} \\
P_{G}^{t}-P_{D}^{t}=B^{t} \cdot \theta^{t} \\
P_{G}^{t}-P_{G}^{0}=\Delta P_{G}
\end{gathered}
$$

$$
\begin{aligned}
& P_{D}^{t}-P_{D}^{0}=\Delta P_{D} \\
& B^{t}-B^{0}=\Delta \mathrm{B} \\
& \theta^{t}-\theta^{0}=\Delta \theta
\end{aligned}
$$

\section{III.4. Constraints}

There are two kinds of constraints, investment and operating. Investment constraints are used to determine the type of technology which is needed and the capacity of the generating units and transmission lines. The investment constraints of the model are stated in equation (12) to (15).

The constraints in (12) determine the additional generating capacity to meet the demand in the system. These constraints are used to represent the capacity of the generating unit as a discrete decision variable because generating units are typically built in blocks of preset size. The size and type of the generating units that will be added are determined by $B i n_{i, g t, n g, q}^{G}$. Each option for a generating unit is only selected once in generating unit technology and the number in each bus. This condition will be achieved by the implementation of constraint (13). Constraint (14) is used to define $B i n_{i, g t, n g, q}^{G}$ as a binary variable. In the same way, the number of transmission lines that will be added is determined by binary variable $\operatorname{Bin}_{i, j, n c}^{L}$ as stated in constraint (15). This binary variable will directly involve the total cost of line investment of the objection function:

$$
\begin{gathered}
N P G_{i, g t, n g}^{\max }=\sum_{q} \operatorname{Bin}_{i, g t, n g, q}^{G} N P G_{i, g t, q}^{\text {opt }} \\
\sum_{q} \operatorname{Bin}_{i, g t, n g, q}^{G} \leq 1 \\
\operatorname{Bin}_{i, g t, n g, q}^{G} \in\{0,1\} \\
\operatorname{Bin}_{i, j, n c}^{L} \in\{0,1\}
\end{gathered}
$$

Operating constraints consist of power flow, power flow limits through existing and new lines and the limit of power generated by each generating unit. Operating constraints are implemented for all load operating conditions. Constraints related to power flow through existing and candidate line are stated in (16). Power flow through corresponding transmission lines is limited by constraints (17). Power quantity will be produced by existing and new generating units which are bounded by constraint (18) and (19) respectively:

$$
\begin{gathered}
P L_{i, j}=\left(U_{i, j}^{E L}+U_{i, j, n c}^{N L}\right) B_{i, j}\left(\theta_{i}-\theta_{j}\right) \\
\left|P L_{i, j}\right| \leq\left(U_{i, j}^{E L}+U_{i, j, n c}^{N L}\right) P L_{i, j}^{\max } \\
0 \leq P G_{i, g t}^{E} \leq E G_{i, g t}^{\max }
\end{gathered}
$$




$$
0 \leq P G_{i, g t}^{N} \leq \sum_{n g} N P G_{i, g t, n g}^{\max }
$$

Electricity produced by each generating unit is defined by the constraint in equation (20). The total electricity production of all generating units (existing and newly built) should meet demand load at peak operation point. Therefore, the sum of electricity production of all generating units must be greater or equal to the total electricity demand (TED) in the system. This is stated in constraint (21). On the other hand, the total capacity of the generating unit must meet the determined reserve margin. This situation can be achieved by implementing constraint (22) in the model:

$$
\begin{gathered}
W_{i, g t, n g}^{G} \leq C F_{g t} \operatorname{MaxOH}_{g t}\left(E P G_{i, g t}^{M a x}+N P G_{i, g t, n g}^{M a x}\right) \\
\sum_{i} \sum_{g t} \sum_{n g} W_{i, g t, n g}^{G} \geq T E D \\
\sum_{i} \sum_{g t} E P G_{i, g t}^{\text {Max }}+\sum_{i} \sum_{g t} \sum_{n g} N P G_{i, g t, n g}^{\text {Max }} \\
\leq(1+M R M) \sum_{d, o \mid o=p e a k} P D_{d, o}^{\text {Max }}
\end{gathered}
$$

\section{III.5. DG Implementation}

In this proposed model, DG will be implemented as a negative load. In this manner, DG will reduce power demand in all buses with load. DG implementation will change the objective function of the model and several constraints will also be added. The objective function in equation (1) should be modified by adding DG investment as a new part of this equation. Therefore, the objective function will be as seen in equation (23) where $D G_{i, d g t, n d g}^{i n v}$ is the investment cost of DG. The definition of $D G_{i, d g t, n d g}^{i n v}$ is stated in equation (24). The operating cost of DG should also be included in the objective function of the model. The operating cost of DG units is $D G_{i, d g t, n d g}^{o p t}$ and is stated equation (25):

$$
\begin{gathered}
\min \left(N G^{i n v}+G^{O M}+N L^{i n v}+G^{E C}+D G^{i n v}\right. \\
\left.+D G^{O M}\right)
\end{gathered}
$$

$$
\begin{aligned}
& D G^{i n v} \\
& =\sum_{i} \sum_{d g t} \sum_{n d g} \sum_{d g q} N D G C_{d g t, q d g}^{O p t} \operatorname{Bin}_{i, d g t, n d g, q d g}^{D G} \\
& D G^{\text {OM }} \\
& =\sum_{o} P D \text { Hour }_{o} \sum_{i} \sum_{d g t} P D G_{i, d g t} \text { VarOMD }_{d g t}
\end{aligned}
$$

The power balance constraint in equation (7) should be modified to accommodate DG installation in the possible bus that will adjust network demand.
This constraint is seen in equation (26). This constraint will treat DG as negative load in all buses with load to reduce local load if it is feasible to install a DG. Similar to the generation unit, DG capacity is predetermined as blocks therefore constraints to select which DG capacity will be installed should be added in the model.

The production of DG should be limited to the chosen DG capacity. To determine a feasible capacity for the DG units, $P D G_{i, d g t}^{\max }$, is defined in equation (27). DG will have an effect on electricity production in the system. Therefore, electricity generated by DG should be considered in constraint (21):

$$
\begin{gathered}
P_{G}^{t}-\left(P_{D}^{t}-P_{D G}^{t}\right)=B^{t} \cdot \theta^{t} \\
P D G_{i, d g t}^{\max }=\sum_{q d g} B i n_{i, d g t, n d g, q d g}^{D G} P D G_{i, d g t, q d g}^{O p t}
\end{gathered}
$$

\section{III.6. Complete Model}

The complete G-TEP model with DG implementation that was described in the previous section can be summarized as follows:

Objective function

subjected to:

\{Equation (20)\}

$$
\begin{gathered}
\{\text { Equations }(2)-(4)\} \\
\{\text { Equations }(12)-(19)\} \\
\{\text { Equations }(21)-(24)\}
\end{gathered}
$$

This model is a MINLP where there is a product of a continuous variable and a binary variable in constraint (16).

To reduce computation burden, MINLP can be converted to MILP by a linearizing constraint (16). This is done using equation (16) for the installed and prospective line. The result of linearization is stated in equations $(28)-(31)$.

For installed lines:

$$
\begin{gathered}
P L_{i, j}=U_{i, j}^{E L} B_{i, j}\left(\theta_{i}-\theta_{j}\right) \\
\left|P L_{i, j}\right| \leq U_{i, j}^{E L} P L_{i, j}^{\max }
\end{gathered}
$$

For prospective lines:

$$
\begin{gathered}
\left|P L_{i, j}-B_{i, j}\left(\theta_{i}-\theta_{j}\right)\right| \leq M\left(1-B i n_{i, j, n c}^{N L}\right) \\
\left|P L_{i, j}\right| \leq B i n_{i, j, n c}^{N L} P L_{i, j}^{\max }
\end{gathered}
$$

Based on the results of linearization, the G-TEP model in the form of MILP can be summarized as follows: 
Objective function

subjected to:

$$
\text { \{Equation (20)\} }
$$

$$
\begin{gathered}
\{\text { Equations }(2)-(4)\} \\
\{\text { Equations }(12)-(15)\} \\
\{\text { Equations }(17)-(19)\} \\
\{\text { Equations }(21)-(23)\} \\
\{\text { Equations }(25)-(28)\}
\end{gathered}
$$

The flowchart that describes the operation of the model is shown in Fig. 2.

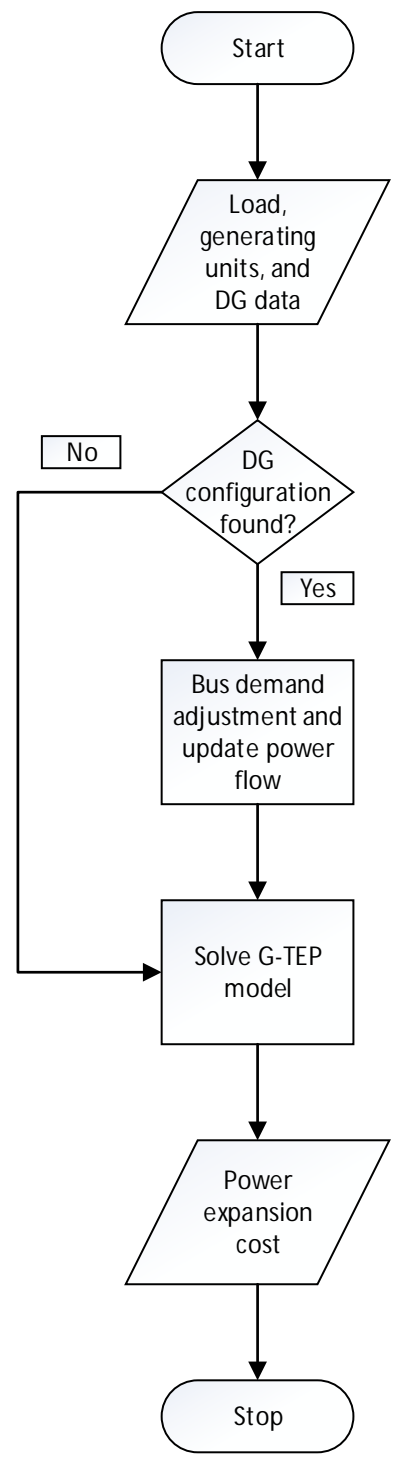

Fig. 2. The flowchart of the model with DG implementation

Input data is consisted of expected load, generating unit, and DG unit. Model will detect weather DG is feasible to be included in the system or not. When DG configuration was found, model will adjust the load data in each bus since DG was model as negative load. Based on adjusted load with the presence of DG, power flow equation will be updated to determine power balance in each bus. Next step, the model of GTEP will be solved to result the optimal overall cost of power expansion planning. The minimum cost will be the result to indicate the optimal configuration of the network based on expected load.

This model is solved by the CPLEX solver for MILP and is implemented under the Advanced Interactive Multidimensional Modelling Systems (AIMMS). The optimality relative tolerance was set to 0.001 .

\section{Cases Study}

\section{IV.1. Garver's 6 Bus System}

In this section, the simulation results are provided to demonstrate the application of the proposed model. The case study used is Garver's 6 Bus system which was originally published in [23]. The modified Garver's test system in Fig. 3 shows the existing power system which is to be expanded in the future to meet the growth in electricity demand. A new bus 6 will be added to the system to meet the total demand. This new bus is not currently connected in the existing system. The proposed model will calculate the minimum number of generating units to be added in the network expansion.

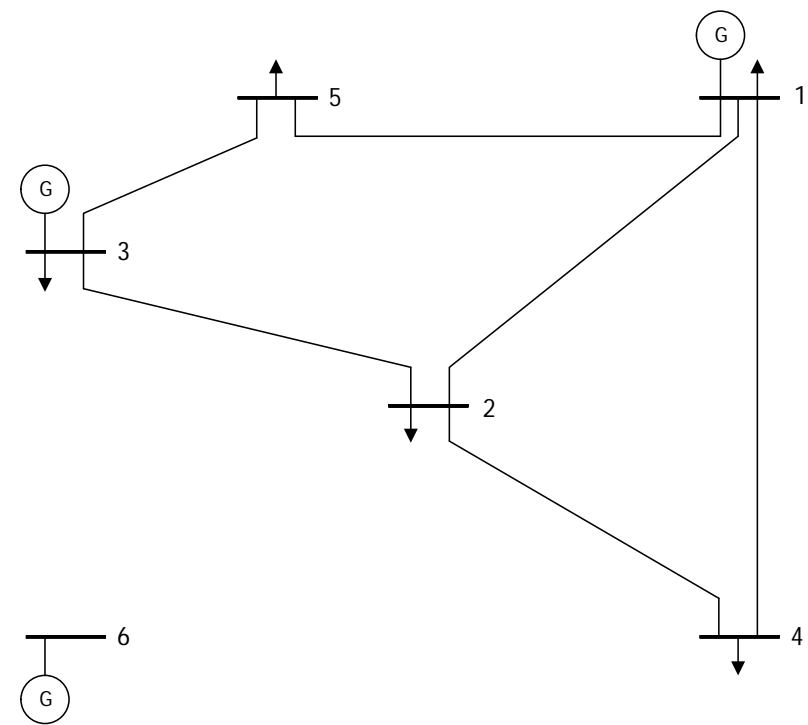

Fig. 3. Garver's 6 bus system

The current generation and demand data is presented in Table I. As the model incorporates a DC load model, power losses are not considered in this analysis. Line data for the existing system are shown in Table II. Each line is limited to their capacity as shown in the fourth column of Table II. To meet projected demand, there are four possible line additions to the system.

\section{IV.2. IEEE 46 Bus Test System}

IEEE 46 bus system was published in [24] which compares and tests the reliability analysis of power systems. 
TABLE I

GENERATION AND LOAD DATA OF EXISTING SYSTEM

\begin{tabular}{cccc}
\hline \hline Bus & $\boldsymbol{C a p}^{\boldsymbol{m a x}}(\mathbf{M W})$ & $\begin{array}{l}\text { Op. Cost } \\
(\$ / \mathbf{M W})\end{array}$ & $P_{d}^{D}(\mathbf{M W})$ \\
\hline 1 & 50 & 18 & 100 \\
2 & - & - & 300 \\
3 & 165 & 25 & 75 \\
4 & - & - & 200 \\
5 & - & - & 275 \\
\hline \hline
\end{tabular}

TABLE II

LINE DATA OF EXISTING SYSTEM

\begin{tabular}{cccc}
\hline \hline From Bus & To Bus & $\boldsymbol{x}_{\boldsymbol{l}}(\mathbf{p u})$ & $\mathbf{F}_{]}^{\text {Max }}(\mathbf{M W})$ \\
\hline 1 & 2 & 0.4 & 100 \\
1 & 4 & 0.6 & 80 \\
1 & 5 & 0.2 & 100 \\
2 & 3 & 0.2 & 100 \\
2 & 4 & 0.4 & 100 \\
3 & 5 & 0.2 & 100 \\
\hline \hline
\end{tabular}

A modified version of this test is suitable for test generation and transmission expansion planning. This test system includes data that is required by the generation and transmission expansion model. Line data includes line impedance, bus to bus line connection, line capacity, line length, and line reliability. The expected annual peak load of the system is 6,880 MW. This peak load capacity represents the load in 4 years to come. The total current generating unit capacity is 5,273 MW which consists of 12 generators. Details on the system configuration, generating unit data, line data, and load data in each bus can be found in the appendix. This test system was modified to suit the developed model. The modified data are the new transmission line cost and capacity. These modifications were made to show the effect of DG implementation on the expansion of an electrical power system.

\section{Results and Discussion}

\section{V.1. Simulation Data}

For simulation purposes, several assumptions should be included to complete the data on the test system. In the simulation, LDC consists of only 2 load levels, which are base and peak load. Base load is determined as half of peak load. The time duration of base and peak load levels is 6,000 and 2,760 hours respectively.

To meet expected electricity demand, additional generating units should be added to the system. The prospective generating units are shown in Table III. The types of prospective generating units are Ultra Supercritical Coal (USC), Gas Turbine (GT), Natural Gas Combined Cycle (NGCC), Hydropower, and Nuclear. This table consists of capital cost and cost of fixed and variable operating and maintenance costs. The performance data on the generating units include Force Outage Rate (FOR) and Planned Outage Rate (POR). FOR and POR will determine the maximum availability of each type of generating unit technology.

This table also shows the environmental impact of electricity generation for each technology. Table IV provides the cost and performance data for DG technology which consist of photovoltaic (PV), wind turbine (WT), and biomass. There is no environmental impact by DG technology in generating electricity. Table III and Table IV were published in [25]. The externality cost regarding each type of emission can be found in [26]. These data will be used in G-TEP simulation for Garver's 6 bus system and IEEE 46 bus test system.

\section{V.2. Simulation Result of Garver's 6 Bus System}

For Garver's 6 bus system, the G-TEP simulation has an additional assumption regarding the availability of renewable sources. Hydropower can only be built in bus 3 and with a maximum capacity of $100 \mathrm{MW}$. Photovoltaic can only be built in bus 1 and 3 while a wind turbine can only be built in bus 2 and 4 . Biomass DG has a maximum capacity of $50 \mathrm{MW}$ and can only be built in bus 5 .

The prospective line in the G-TEP simulation for Garver's 6 bus system is shown in Table V. Each line is limited to its capacity, as shown in the fourth column of the table. To meet projected demand, the G-TEP model should have the ability to determine whether additional lines are needed not only for the new circuit but also for line reinforcement in the form of a parallel circuit.

TABLE III

COST AND PERFORMANCE OF PROSPECTIVE GENERATING UNITS

\begin{tabular}{|c|c|c|c|c|c|c|c|c|}
\hline Technology & $\begin{array}{c}\text { Capital Cost } \\
(\$ / \mathrm{kW})\end{array}$ & $\begin{array}{c}\text { Fixed O\&M } \\
(\$ / k W-y r)\end{array}$ & $\begin{array}{l}\text { Var. O\&M } \\
\text { (\$/MWh) }\end{array}$ & $\begin{array}{c}\mathbf{S O}_{2} \\
\text { (lb/MMBtu) }\end{array}$ & $\begin{array}{c}\text { NO }_{\mathbf{x}} \\
\text { (lb/MMBtu) }\end{array}$ & $\begin{array}{c}\text { CO2 } \\
\text { (lb/MMBtu) }\end{array}$ & FOR (\%) & POR (\%) \\
\hline USC & 3,636 & 42.1 & 4.6 & 0.1 & 0.06 & 206 & 6 & 10 \\
\hline GT & 1,104 & 17.5 & 3.5 & 0.001 & 0.03 & 117 & 3 & 5 \\
\hline NGCC & 978 & 11 & 3.5 & 0.001 & 0.0075 & 117 & 4 & 6 \\
\hline Hydro & 3,487 & 15 & 6 & - & - & - & 5 & 1.9 \\
\hline Nuclear & 5,945 & 100.28 & 2.3 & - & - & - & 4 & 6 \\
\hline
\end{tabular}

TABLE IV

COST AND PERFORMANCE DATA FOR DG TECHNOLOGY

\begin{tabular}{lrrrrr}
\hline \hline Technology & $\begin{array}{c}\text { Capital Cost } \\
(\mathbf{\$} / \mathbf{k W})\end{array}$ & $\begin{array}{c}\text { Fixed O\&M } \\
(\mathbf{\$} / \mathbf{k W}-\mathbf{y r})\end{array}$ & $\begin{array}{c}\text { Var. O\&M } \\
(\mathbf{\$} / \mathbf{M W h})\end{array}$ & FOR (\%) & POR (\%) \\
\hline WT & 1,877 & 39.7 & - & 2 & - \\
PV & 2,671 & 23.4 & - & 0.6 & 5 \\
Biomass & 990 & 20 & - & 7 & 9 \\
\hline \hline
\end{tabular}


TABLE V

PROSPECTIVE LINE CHARACTERISTICS

\begin{tabular}{ccccc}
\hline \hline From Bus & To Bus & $\boldsymbol{x}_{\boldsymbol{l}}(\mathbf{p u})$ & $\begin{array}{c}\mathbf{F}_{1}^{\text {Max }} \\
(\mathbf{M W})\end{array}$ & $\begin{array}{c}\text { Line Cost } \\
(\mathbf{1 0} \mathbf{6} \mathbf{\$})\end{array}$ \\
\hline 1 & 2 & 0.4 & 100 & 40 \\
1 & 3 & 0.6 & 80 & 60 \\
1 & 4 & 0.2 & 100 & 20 \\
1 & 5 & 0.2 & 100 & 20 \\
1 & 6 & 0.4 & 100 & 40 \\
2 & 3 & 0.2 & 100 & 20 \\
2 & 4 & 0.3 & 100 & 38 \\
2 & 5 & 0.68 & 70 & 68 \\
2 & 6 & 0.31 & 100 & 31 \\
3 & 4 & 0.3 & 100 & 30 \\
3 & 5 & 0.59 & 82 & 59 \\
3 & 6 & 0.48 & 100 & 48 \\
4 & 5 & 0.63 & 75 & 63 \\
4 & 6 & 0.3 & 100 & 30 \\
5 & 6 & 0.61 & 78 & 61 \\
\hline \hline
\end{tabular}

The simulation results for Garver's 6 bus system are shown in Table VI and Table VII. The optimal expansion of the power system without DG implementation is shown in Table VI. Table VI-A shows that a generation unit must be added with a total capacity of 220 MW.A new generation unit must be installed at bus 1 and bus 5 with a capacity of $180 \mathrm{MW}$ of NGCC and $40 \mathrm{MW}$ of CT respectively. The new CT will only be operated to provide electricity at peak load condition, whereas the new NGCC will operate at all load condition with operating capacity of $175 \mathrm{MW}$ and $180 \mathrm{MW}$ for base and peak load, respectively.

An additional line must be installed to meet the expected electricity demand. For optimal expansion, two new lines connecting bus $2-6$ and bus $4-6$ need to be added. Each new line has 2 parallel circuits with reactance and capacity as shown in Table VI-B. By adding these two new lines, bus 6 will now be connected to the system. In relation to expansion cost, the total cost for optimal configuration without DG implementation is $196.21 \times 10^{6}$ USD. The total cost of power system expansion consists of the O\&M cost of the generating unit, the new generating unit investment cost, externality cost of the generating unit, and new line investment cost. Details of these costs are shown in Table VI-C.

TABLE VI

OPTIMAL EXPANSION FOR GARVER'S SYSTEM WITHOUT DG IMPLEMENTATION

\begin{tabular}{|c|c|c|c|c|}
\hline \multirow[t]{2}{*}{ Bus No. } & \multirow[t]{2}{*}{ Technology } & \multirow{2}{*}{$\begin{array}{c}\text { Capacity } \\
\text { (MW) }\end{array}$} & \multicolumn{2}{|c|}{ "Operating Point } \\
\hline & & & Base & Peak \\
\hline 1 & NGCC & 180 & 175 & 180 \\
\hline 5 & GT & 40 & 0 & 40 \\
\hline \multicolumn{5}{|c|}{ B. Transmission Line Addition } \\
\hline From-to B & Reactan & \multicolumn{3}{|c|}{ Capacity (MW) } \\
\hline $2-6$ & & \multicolumn{3}{|c|}{$2 \times 100$} \\
\hline $4-6$ & & \multicolumn{3}{|c|}{$2 \times 100$} \\
\hline \multicolumn{5}{|c|}{ C. Expansion Cost } \\
\hline \multicolumn{3}{|c|}{ Cost Type } & \multicolumn{2}{|c|}{ Cost $\left(\times 10^{6}\right.$ USD $)$} \\
\hline \multicolumn{3}{|c|}{ Total Generator O\&M Cost } & \multicolumn{2}{|c|}{62} \\
\hline \multicolumn{3}{|c|}{ Total Generator Investment Cost } & \multicolumn{2}{|r|}{2.21} \\
\hline \multicolumn{3}{|c|}{ Total Line Investment Cost } & \multicolumn{2}{|r|}{120} \\
\hline \multicolumn{3}{|c|}{ Total Externality Cost } & \multicolumn{2}{|r|}{12} \\
\hline \multicolumn{3}{|c|}{ Total Cost } & \multicolumn{2}{|r|}{196.21} \\
\hline
\end{tabular}

Table VII shows the optimal system configuration after the expansion of the power system with DG implementation. In contrast to the previous results, three additional generating units must be installed, these being $135 \mathrm{MW}$ of NGCC at bus 1, $40 \mathrm{MW}$ of GT at bus 2, and $50 \mathrm{MW}$ of GT at bus 5. A new NGCC is used for both base and peak load level with an operating point of 120 MW and $135 \mathrm{MW}$, respectively. A new GT at bus 2 and bus 5 will only operate at peak load level. In addition, three types of DG technology must be installed, which are $4 \times 10 \mathrm{MW}$ of WT in bus 2 and bus 4 and $4 \times 10 \mathrm{MW}$ of biomass in bus 5 .

TABLE VII

OPTIMAL EXPANSION FOR GARVER's SYSTEM WITH DG IMPLEMENTATION

\begin{tabular}{|c|c|c|c|}
\hline \multirow[t]{2}{*}{ Bus No. } & \multirow{2}{*}{$\begin{array}{c}\text { Generator } \\
\text { Technology }\end{array}$} & \multirow{2}{*}{$\begin{array}{c}\text { Capacity } \\
\text { (MW) }\end{array}$} & Operating Point \\
\hline & & & Peak \\
\hline 1 & NGCC & 135 & 135 \\
\hline 2 & GT & 40 & 40 \\
\hline 5 & GT & 50 & 50 \\
\hline \multicolumn{4}{|c|}{ B. DG Addition } \\
\hline From-to & Reactance (p.u.) & \multicolumn{2}{|c|}{ Capacity (MW) } \\
\hline $4-6$ & $2 \times \mathrm{j} 0.3$ & \multicolumn{2}{|c|}{$2 \times 100$} \\
\hline \multicolumn{4}{|c|}{ C. Transmission Line Addition } \\
\hline Bus No. & $\begin{array}{l}\text { DG Technology } \\
\end{array}$ & \multicolumn{2}{|c|}{ Capacity (MW) } \\
\hline 2 & WT & & $4 \times 10$ \\
\hline 4 & WT & & $4 \times 10$ \\
\hline 5 & Biomass & & $4 \times 10$ \\
\hline \multicolumn{4}{|c|}{$\begin{array}{ll}\text { D. } & \text { Expansion Cost } \\
\end{array}$} \\
\hline \multicolumn{2}{|c|}{$\begin{array}{l}\text { Cost Type } \\
\end{array}$} & \multicolumn{2}{|c|}{ Cost $\left(\times 10^{6}\right.$ USD $)$} \\
\hline \multicolumn{2}{|c|}{ Total Generator O\&M Cost } & \multicolumn{2}{|c|}{58.8} \\
\hline \multicolumn{2}{|c|}{ Total Generator Investment Cost } & \multicolumn{2}{|r|}{3.31} \\
\hline \multicolumn{2}{|c|}{ Total Line Investment Cost } & \multicolumn{2}{|r|}{60} \\
\hline \multicolumn{2}{|c|}{ Total Externality Cost } & \multicolumn{2}{|r|}{9.38} \\
\hline \multicolumn{2}{|c|}{ Total DG O\&M Cost } & \multicolumn{2}{|r|}{3.98} \\
\hline \multicolumn{2}{|c|}{ Total DG Investment Cost } & \multicolumn{2}{|r|}{19} \\
\hline \multicolumn{2}{|c|}{ Total Cost } & \multicolumn{2}{|r|}{154.47} \\
\hline
\end{tabular}

The addition of DG will reduce demand as DG is treated as a negative load in each demand bus. After expansion, the network is configured differently. Table VII-C shows that only one new line has been added to connect bus 4 and bus 6 . This new line consists of two parallel circuits. Its characteristics are detailed in the table. DG implementation also has an impact on the expansion cost of the power system. Table VII-D shows that the investment cost of the new generating unit is slightly higher compared to the previous result and there are additional costs of DG investment and O\&M. However, the O\&M cost for all the generating units is less because of reducing the investment cost of the transmission line. The externality cost of the generating units is also comparably reduced. The overall expansion of the system with DG implementation is $154.47 \times 10^{6}$ USD. Compared to the previous expansion result, DG implementation will reduce overall expansion cost by $21,27 \%$.

\section{V.3. Simulation Result of IEEE 46 Bus Test System}

Simulation with the IEEE 46 bus test system was done using several assumptions related to renewable energy 
sources. Hydropower can only be built at bus 20, 24, and 42 with a total capacity of $300 \mathrm{MW}$. PV can only be built at bus 33 and 42 . WT is at bus 1 , bus 3 , and bus 5 , while a biomass-based power plant will be built at bus 2, bus 9, and bus 12. The configuration of the installed and prospective transmission line is shown in Table A2 in the appendix. The number of parallel line of installed transmission line is indicated by data of circuit number. While the prospective transmission line has no data in the column of circuit number.

The simulation results of IEEE 46 bus test system without and with DG implementation are shown in Table VIII and Table IX, respectively. Table VIII-A shows that four different types of generator technology were installed, which added 4,015 MW to the system. The total capacity of the existing and newly installed generating units is $8,940 \mathrm{MW}$.

TABLE VIII

OPTIMAL EXPANSION RESULT OF IEEE 46 BUS WiTHOUT DG IMPLEMENTATION

\begin{tabular}{cccc} 
A. Generator Addition & \multicolumn{3}{c}{ Operating Point (MW) } \\
Peak
\end{tabular}

At expected peak load, there will be a surplus capacity of $29.94 \%$. This surplus capacity is the result of determining the reserve margin with a maximum value of $30.00 \%$. The total investment cost of the new generating units is $33.040 \times 10^{6} \mathrm{USD}$.

Without DG implementation, four transmission lines need to be added, as shown in Table VIII-B. The lines to connect bus $18-19$, bus $19-21$, and bus $40-14$ need to be single circuited lines with a capacity of $300 \mathrm{MW}, 150$ MW, and $300 \mathrm{MW}$, respectively. The line to connect bus 31-41 needs to be a double circuited line with a capacity of $2 \times 150 \mathrm{MW}$. The total cost of new line investment is $261.00 \times 10^{6}$ USD.
The overall cost of system expansion without DG implementation for the IEEE 46 bus test system is $1,293.20 \times 10^{6}$ USD. This overall cost consists of the investment cost of new generating units and transmission lines as previously discussed, the O\&M cost of existing and newly installed generating units, and the externality cost of electricity production. Details of the expansion cost are in Table VIII-C.

The optimal expansion planning of the IEEE 46 bus test system with DG implementation is shown in Table IX.

TABLE IX

OPTIMAL EXPANSION RESULT OF IEEE 46 BUS WITH DG IMPLEMENTATION

\begin{tabular}{|c|c|c|c|}
\hline \multirow[t]{2}{*}{ Bus No. } & \multirow[t]{2}{*}{ Capacity (MW) } & \multicolumn{2}{|c|}{ "Operating Point } \\
\hline & & Base & Peak \\
\hline 1 & 60 (GT) & 0 & 60 \\
\hline 8 & $\begin{array}{c}60(\mathrm{GT})+135 \\
(\mathrm{NGCC})\end{array}$ & 58 & 135 \\
\hline 20 & $\begin{array}{c}200 \text { (NGCC) }+850 \\
\text { (Nuclear) }\end{array}$ & 1,034 & 1,050 \\
\hline 23 & $180+200(\mathrm{NGCC})$ & 380 & 380 \\
\hline 24 & $\begin{array}{c}50(\mathrm{GT})+200 \\
(\mathrm{NGCC})\end{array}$ & 200 & 250 \\
\hline 33 & $\begin{array}{c}60(\mathrm{GT})+200 \\
(\mathrm{NGCC})\end{array}$ & 200 & 260 \\
\hline 34 & $2 \times 60(\mathrm{GT})$ & 0 & 120 \\
\hline 35 & $2 \times 60(\mathrm{GT})$ & 0 & 120 \\
\hline 38 & $40(\mathrm{GT})$ & 0 & 40 \\
\hline 39 & $2 \times 60(\mathrm{GT})$ & 0 & 120 \\
\hline 40 & $\begin{array}{c}40(\mathrm{GT})+180 \\
(\mathrm{NGCC})\end{array}$ & 0 & 220 \\
\hline 42 & $\begin{array}{c}200 \text { (NGCC) + 1,000 } \\
\text { (Nuclear) }\end{array}$ & 1,000 & 1,200 \\
\hline \multicolumn{4}{|c|}{ B. $\quad$ DG Addition } \\
\hline Bus No. & DG Technology & & (MW) \\
\hline 1 & WT & & $4 \times 6$ \\
\hline 2 & Biomass & & $4 \times 15$ \\
\hline 5 & WT & & $4 \times 6$ \\
\hline 9 & Biomass & & 15 \\
\hline 33 & PV & & 5 \\
\hline 42 & PV & & $3 \times 5$ \\
\hline \multicolumn{4}{|c|}{ C. Transmission Line Addition } \\
\hline From-to Bus & Reactance (p.u.) & Capaci & \\
\hline $18-19$ & $1 \times \mathrm{j} 0.0125$ & & \\
\hline $19-21$ & $1 \times \mathrm{j} 0.0278$ & & \\
\hline $32-43$ & $1 \times \mathrm{j} 0.0309$ & & \\
\hline \multicolumn{4}{|c|}{ D. $\quad$ Expansion Cost } \\
\hline & Cost Type & & USD) \\
\hline Total Generatc & r O\&M Cost & & 932 \\
\hline Total Generatc & r Investment Cost & & 33 \\
\hline Total Line Inv & estment Cost & & 150 \\
\hline Total External & ity Cost & & 60.6 \\
\hline Total DG O\&I & M Cost & & 13.4 \\
\hline Total DG Inve & stment Cost & & 50.6 \\
\hline Total Cost & & & $1,239.61$ \\
\hline
\end{tabular}

It can be seen that the system configuration after expansion with DG implementation has different results compared to expansion without DG implementation. The additional generation units which are needed to supply the expected demand have a total capacity of 4,015 MW. This total capacity is the same as the previous result but with a different configuration due to the different generator technology and location. The overall capacity 
of the system's generating units and the selected reserve margin also have the same results, which are 8,940 MW and $29.94 \%$, respectively. The total investment cost of the new generating units is $33.00 \times 10^{6}$ USD. Additional detail on the generator technology is shown in Table IXA. Furthermore, three different types of DG technology need to be built in four buses. WT needs to be built at bus 1 and bus 5 with the capacity of $4 \times 6 \mathrm{MW}$ in each bus. A biomass-based power plant will have to be built at bus 2 and bus 9 with the capacity of $3 \times 15 \mathrm{MW}$ and $2 \times$ $15 \mathrm{MW}$, respectively. PV will be built at bus 33 and bus 42 with the capacity of $5 \mathrm{MW}$ and $3 \times 15 \mathrm{MW}$, respectively. The total investment of the newly installed DG is $50.6 \times 10^{6}$ USD.

Compared to expansion without DG implementation, only three additional transmission lines are needed in the system. Lines connecting bus 18-19 and bus 19-21 are still needed for the expansion with DG implementation with the same capacity. An additional line to connect bus $32-43$ is needed with a capacity of $140 \mathrm{MW}$. The total investment for the new transmission lines is $150 \times 10^{6}$ USD. Details on the additional transmission lines are shown in Table IX-C.

The overall expansion cost of the IEEE 46 bus test system is $1,239.60 \times 10^{6}$ USD. Compared to the previous result, expansion with DG implementation will reduce the overall expansion cost by $4.15 \%$. Overall cost reductions are due to a reduction in the generating O\&M cost, transmission line investment, and externality cost. These cost reductions have a greater impact than the additional cost of DG investment and O\&M cost. Details of the expansion cost of the IEEE 46 bus test system are shown in Table IX-D.

\section{Conclusion}

An integrated model for generation and transmission expansion planning was implemented in a 6-bus and 46- bus system. The objective of the model is to minimize the overall cost of the system by allocating new generating units and transmission lines. The problem was formulated in the form of MILP. The benefits of this formulation are that the exact location and capacity of the new power plant can be determined together with the additional transmission line, and the distributed generation location can be determined based on the potential of each local resource. The simulation results of the integrated model show that the DG implementation will change the network configuration and reduce the overall cost of the system. DG implementation will reduce the overall expansion cost of the electrical power system by $21.27 \%$ and $4.15 \%$ for Garver's 6 bus system and IEEE 46 bus test system, respectively. Compared to the previous work, the model proposed in this study can be used to perform a comparison of power system expansion planning without and with DG implementation. This model can be used by governments or policy makers in power system expansion to access the correct information regarding suitable DG technologies in each bus or area.

The impact of DG on expansion planning in electrical power systems can be investigated using the multiperiod G-TEP model. The model also can be improved to accommodate stochastic variables. Moreover, the impact of DG on the reliability of power systems from the view of expansion planning can also be investigated with a modification of the proposed model.

\section{Acknowledgements}

We gratefully acknowledge the funding from USAID through the SHERA program - Centre for Development of Sustainable Region (CDSR).

\section{Appendix}

TABLE A1

GENERATION AND LOAD DATA OF IEEE 46 Bus TEST SYSTEM

\begin{tabular}{|c|c|c|c|c|c|c|c|}
\hline$\overline{\text { Bus }}$ & $\begin{array}{l}\text { Generation, MW } \\
\text { Maximum Level }\end{array}$ & & Load, MW & Bus & $\begin{array}{l}\text { Generation, MW } \\
\text { Maximum Level }\end{array}$ & & Load, MW \\
\hline 1 & 0 & 0 & 0 & 24 & 0 & 0 & 478.2 \\
\hline 2 & 0 & 0 & 443.1 & 25 & 0 & 0 & 0 \\
\hline 3 & 0 & 0 & 0 & 26 & 0 & 0 & 231.9 \\
\hline 4 & 0 & 0 & 300.7 & 27 & 110 & 27 & 0 \\
\hline 5 & 0 & 0 & 238 & 28 & 400 & 365 & 0 \\
\hline 6 & 0 & 0 & 0 & 29 & 0 & 0 & 0 \\
\hline 7 & 0 & 0 & 0 & 30 & 0 & 0 & 0 \\
\hline 8 & 0 & 0 & 72.2 & 31 & 350 & 155 & 0 \\
\hline 9 & 0 & 0 & 0 & 32 & 250 & 225 & 0 \\
\hline 10 & 0 & 0 & 0 & 33 & 0 & 0 & 229.1 \\
\hline 11 & 0 & 0 & 0 & 34 & 374 & 111 & 0 \\
\hline 12 & 0 & 0 & 511.9 & 35 & 0 & 0 & 216 \\
\hline 13 & 0 & 0 & 185.8 & 36 & 0 & 0 & 90.1 \\
\hline 14 & 629 & 472 & 0 & 37 & 150 & 106 & 0 \\
\hline
\end{tabular}




\begin{tabular}{|c|c|c|c|c|c|c|c|}
\hline Bus & $\begin{array}{l}\text { Generation, MW } \\
\text { Maximum Level }\end{array}$ & & Load, MW & Bus & $\begin{array}{l}\text { Generation, MW } \\
\text { Maximum Level }\end{array}$ & & Load, MW \\
\hline 15 & 0 & 0 & 0 & 38 & 0 & 0 & 216 \\
\hline 16 & 1000 & 683 & 0 & 39 & 300 & 111 & 0 \\
\hline 17 & 525 & 500 & 0 & 40 & 0 & 0 & 262.1 \\
\hline 18 & 0 & 0 & 0 & 41 & 0 & 0 & 0 \\
\hline 19 & 835 & 387 & 0 & 42 & 0 & 0 & 1607.9 \\
\hline 20 & 0 & 0 & 1091.2 & 43 & 0 & 0 & 0 \\
\hline 21 & 0 & 0 & 0 & 44 & 0 & 0 & 79.1 \\
\hline 22 & 0 & 0 & 81.9 & 45 & 0 & 0 & 86.7 \\
\hline 23 & 0 & 0 & 458.1 & 46 & 350 & 300 & 0 \\
\hline
\end{tabular}

TABLE A2

TRANSMission Line Data Of IEEE 46 Bus TeSt System

\begin{tabular}{|c|c|c|c|c|c|c|c|c|c|c|c|}
\hline $\begin{array}{c}\text { From } \\
\text { Bus }\end{array}$ & $\begin{array}{c}\text { To } \\
\text { Bus }\end{array}$ & $\begin{array}{l}\text { Circuit } \\
\text { Number }\end{array}$ & $\begin{array}{c}\text { Reactance } \\
\text { (p.u.) }\end{array}$ & $\begin{array}{l}\text { Capacity } \\
\text { (MW) }\end{array}$ & $\begin{array}{l}\text { Line Cost } \\
\left(10^{6} \text { USD) }\right.\end{array}$ & $\begin{array}{c}\text { From } \\
\text { Bus }\end{array}$ & $\begin{array}{c}\text { To } \\
\text { Bus }\end{array}$ & $\begin{array}{c}\text { Circuit } \\
\text { Number }\end{array}$ & $\begin{array}{c}\text { Reactance } \\
\text { (p.u.) }\end{array}$ & $\begin{array}{l}\text { Capacity } \\
\text { (MW) }\end{array}$ & $\begin{array}{l}\text { Line Cost } \\
\left(10^{6} \text { USD) }\right.\end{array}$ \\
\hline 1 & 2 & 2 & 0.1065 & 270 & 70.76 & 20 & 21 & 1 & 0.0125 & 300 & 81.78 \\
\hline 1 & 7 & 1 & 0.0616 & 270 & 43.49 & 20 & 23 & 2 & 0.0932 & 270 & 62.68 \\
\hline 2 & 3 & 0 & 0.0125 & 300 & 81.78 & 21 & 25 & 0 & 0.0174 & 200 & 21.12 \\
\hline 2 & 4 & 0 & 0.0882 & 270 & 59.65 & 22 & 26 & 1 & 0.079 & 270 & 54.09 \\
\hline 2 & 5 & 2 & 0.0324 & 270 & 25.81 & 23 & 24 & 2 & 0.0774 & 270 & 53.08 \\
\hline 3 & 46 & 0 & 0.0203 & 180 & 24.32 & 24 & 25 & 0 & 0.0125 & 300 & 81.78 \\
\hline 4 & 5 & 2 & 0.0566 & 270 & 40.46 & 24 & 33 & 1 & 0.1448 & 240 & 93.99 \\
\hline 4 & 9 & 1 & 0.0924 & 270 & 62.17 & 24 & 34 & 1 & 0.1647 & 220 & 106.11 \\
\hline 4 & 11 & 0 & 0.2246 & 240 & 142.47 & 25 & 32 & 0 & 0.0319 & 140 & 37.11 \\
\hline 5 & 6 & 0 & 0.0125 & 300 & 81.78 & 26 & 27 & 2 & 0.0832 & 270 & 56.62 \\
\hline 5 & 8 & 1 & 0.1132 & 270 & 74.80 & 26 & 29 & 0 & 0.0541 & 270 & 38.94 \\
\hline 5 & 9 & 1 & 0.1173 & 270 & 77.32 & 27 & 29 & 0 & 0.0998 & 270 & 66.72 \\
\hline 5 & 11 & 0 & 0.0915 & 270 & 61.67 & 27 & 36 & 1 & 0.0915 & 270 & 61.67 \\
\hline 6 & 46 & 0 & 0.0128 & 200 & 160.05 & 27 & 38 & 2 & 0.208 & 200 & 132.37 \\
\hline 7 & 8 & 1 & 0.1023 & 270 & 68.23 & 28 & 30 & 0 & 0.0058 & 200 & 83.31 \\
\hline 8 & 13 & 1 & 0.1348 & 240 & 87.93 & 28 & 31 & 0 & 0.0053 & 200 & 78.19 \\
\hline 9 & 10 & 0 & 0.0125 & 300 & 81.78 & 28 & 41 & 0 & 0.0339 & 130 & 39.28 \\
\hline 9 & 14 & 2 & 0.1756 & 220 & 112.67 & 28 & 43 & 0 & 0.0406 & 120 & 46.70 \\
\hline 10 & 46 & 0 & 0.0081 & 200 & 108.89 & 29 & 30 & 0 & 0.0125 & 300 & 81.78 \\
\hline 11 & 46 & 0 & 0.0125 & 300 & 81.78 & 31 & 32 & 0 & 0.0046 & 200 & 70.52 \\
\hline 12 & 14 & 2 & 0.074 & 270 & 51.06 & 31 & 41 & 0 & 0.0278 & 150 & 32.63 \\
\hline 13 & 18 & 1 & 0.1805 & 220 & 115.70 & 32 & 41 & 0 & 0.0309 & 140 & 35.96 \\
\hline 13 & 20 & 1 & 0.1073 & 270 & 71.26 & 32 & 43 & 1 & 0.0309 & 140 & 35.96 \\
\hline 14 & 15 & 0 & 0.0374 & 270 & 28.84 & 33 & 34 & 1 & 0.1265 & 270 & 82.88 \\
\hline 14 & 18 & 2 & 0.1514 & 240 & 98.03 & 34 & 35 & 2 & 0.0491 & 270 & 35.91 \\
\hline 14 & 22 & 1 & 0.084 & 270 & 57.12 & 35 & 38 & 1 & 0.198 & 200 & 126.31 \\
\hline 14 & 26 & 1 & 0.1614 & 220 & 104.09 & 36 & 37 & 1 & 0.1057 & 270 & 70.25 \\
\hline 15 & 16 & 0 & 0.0125 & 300 & 81.78 & 37 & 39 & 1 & 0.0283 & 270 & 23.29 \\
\hline 16 & 17 & 1 & 0.0078 & 200 & 105.05 & 37 & 40 & 1 & 0.1281 & 270 & 83.89 \\
\hline 16 & 28 & 0 & 0.0222 & 180 & 26.37 & 37 & 42 & 1 & 0.2105 & 200 & 133.88 \\
\hline 16 & 32 & 0 & 0.0311 & 140 & 36.21 & 38 & 42 & 3 & 0.0907 & 270 & 61.16 \\
\hline 16 & 46 & 1 & 0.0203 & 180 & 24.32 & 38 & 44 & 1 & 0.1206 & 270 & 79.34 \\
\hline 17 & 19 & 1 & 0.0061 & 200 & 87.15 & 39 & 42 & 3 & 0.203 & 200 & 129.34 \\
\hline 17 & 32 & 0 & 0.0232 & 170 & 27.52 & 40 & 41 & 0 & 0.0125 & 300 & 81.78 \\
\hline 18 & 19 & 1 & 0.0125 & 300 & 81.78 & 40 & 42 & 1 & 0.0932 & 270 & 62.68 \\
\hline 18 & 20 & 1 & 0.1997 & 200 & 127.32 & 40 & 45 & 0 & 0.2205 & 180 & 139.94 \\
\hline 19 & 21 & 1 & 0.0278 & 150 & 32.63 & 41 & 43 & 0 & 0.0139 & 200 & 172.84 \\
\hline 19 & 25 & 0 & 0.0325 & 140 & 37.75 & 42 & 43 & 1 & 0.0125 & 300 & 81.78 \\
\hline 19 & 32 & 1 & 0.0195 & 180 & 23.42 & 44 & 45 & 1 & 0.1864 & 200 & 119.24 \\
\hline 19 & 46 & 1 & 0.0222 & 180 & 26.37 & & & & & & - \\
\hline
\end{tabular}

\section{References}

[1] J. H. Roh, M. Shahidehpour, and Y. Fu, "Market-based coordination of transmission and generation capacity planning,"
IEEE Transactions on Power Systems, vol. 22, no. 4, 2007, pp. 1406-1419.

[2] B. Alizadeh and S. Jadid, "Reliability constrained coordination of generation and transmission expansion planning in power systems 
using mixed integer programming," IET Generation, Transmission \& Distribution, vol. 5, no. 9, 2011, pp. 948-960.

[3] I. Sharan and R. Balasubramanian, "Integrated generation and transmission expansion planning including power and fuel transportation constraints," Energy Policy, vol. 43, 2012, pp. 275284.

[4] A. Khodaei and M. Shahidehpour, "Microgrid-based cooptimization of generation and transmission planning in power systems," IEEE Transactions on Power Systems, vol. 28, no. 2, 2013, pp. 1582-1590.

[5] D. Pozo, E. E. Sauma, and J. Contreras, "A Three-Level Static MILP Model for Generation and Transmission Expansion Planning," IEEE Transactions on Power Systems, vol. 28, no. 1, 2013, pp. 202-210.

[6] J. Aghaei, N. Amjady, A. Baharvandi, and M.-A. Akbari, "Generation and Transmission Expansion Planning: MILP-Based Probabilistic Model," IEEE Transactions on Power Systems, vol. 29, no. 4, 2014, pp. 1592-1601.

[7] B. Alizadeh and S. Jadid, "A dynamic model for coordination of generation and transmission expansion planning in power systems," International Journal of Electrical Power and Energy Systems, vol. 65, 2015, pp. 408-418.

[8] F. Barati, H. Seifi, M. S. Sepasian, A. Nateghi, M. Shafie-khah, and J. P. S. Catalao, "Multi-Period Integrated Framework of Generation, Transmission, and Natural Gas Grid Expansion Planning for Large-Scale Systems," IEEE Transactions on Power Systems, vol. 30, no. 5, 2015, pp. 2527-2537.

[9] A. Heidari, H. Mavalizadeh, and A. Ahmadi, "Probabilistic multiobjective generation and transmission expansion planning problem using normal boundary intersection," IET Generation, Transmission \& Distribution, vol. 9, no. 6, Apr. 2015, pp. 560570 .

[10] I. Bae and J. Kim, "Reliability Evaluation of Distributed Generation Based on Operation Mode," IEEE Transactions on Power Systems, vol. 22, no. 2, 2007, pp. 785-790.

[11] A. Zangeneh, S. Jadid, and A. Rahimi-kian, "A hierarchical decision making model for the prioritization of distributed generation technologies: A case study for Iran," Energy Policy, vol. 37 , no. 12,2009 , pp. $5752-5763$.

[12] A. P. Agalgaonkar, S. V Kulkarni, and S. a Khaparde, "Evaluation of configuration plans for DGs in developing countries using advanced planning techniques," IEEE Transactions on Power Systems, vol. 21, no. 2, 2006, pp. 973-981.

[13] G. W. Ault and J. R. Mcdonald, "Planning for Distributed Generation within Distribution Networks in Restructured Electricity Markets," IEEE Power Engineering Review, vol. 20, 2000, pp. 52-54.

[14] L. F. Ochoa and G. P. Harrison, "Minimizing Energy Losses $\square$ : Optimal Accommodation and Smart Operation of Renewable Distributed Generation," IEEE Transactions on Power Systems, vol. 26, no. 1, 2011, pp. 198-205.

[15] Hidayat, M., Li, F., Energy-Based Distributed Generation Incentives for Distribution Network Operators, (2016) International Review of Electrical Engineering (IREE), 11 (6), pp. 673-679.

[16] B. Renders, K. De Gussemé, W. R. Ryckaert, K. Stockman, L. Vandevelde, and M. H. J. Bollen, "Distributed Generation for Mitigating Voltage Dips in Low-Voltage Distribution Grids," IEEE Transactions on Power Delivery, vol. 23, no. 3, 2008, pp. 1581-1588.

[17] T. Senjyu, Y. Miyazato, A. Yona, N. Urasaki, and T. Funabashi, "Optimal Distribution Voltage Control and Coordination With Distributed Generation," IEEE Transactions on Power Delivery, vol. 23, no. 2, 2008, pp. 1236-1242.

[18] F. Luo, J. Zhao, J. Qiu, S. Member, and J. Foster, "Assessing the Transmission Expansion Cost With Distributed Generation: An Australian Case Study," IEEE Transactions on Smart GRID, vol. 5, no. 4, 2014, pp. 1892-1904.

[19] J. H. Zhao, J. Foster, Z. Y. Dong, and K. P. Wong, "Flexible transmission network planning considering distributed generation impacts," IEEE Transactions on Power Systems, vol. 26, no. 3, 2011, pp. 1434-1443.

[20] Rios, M., Moreno Garzon, A., Integrated Generation and Transmission Planning with Intermittent Renewable Energy
Sources in High-Level Hydroelectric Generation Systems, (2015) International Review of Electrical Engineering (IREE), 10 (3), pp. 404-413.

[21] A. Rouhani, S. H. Hosseini, and M. Raoofat, "Composite generation and transmission expansion planning considering distributed generation," International Journal of Electrical Power \& Energy Systems, vol. 62, no. July 2015, 2014, pp. 792-805.

[22] X. F. Wang and J. Mcdonald, Modern Power System Planning. New York: McGraw-Hill, 1994

[23] L. L. Garver, "Transmission Network Estimation Using Linear Programming," IEEE Transactions on Power Apparatus and Systems, vol. PAS-89, no. 7, 1970, pp. 1688-1697.

[24] S. Haffner, A. Monticelli, A. Garcia, J. Mantovani and R. Romero, "Branch and bound algorithm for transmission system expansion planning using a transportation model," in IEE Proceedings - Generation, Transmission and Distribution, vol. 147, no. 3, pp. 149-156, May 2000.

[25] Anonymous, "Cost and Performance data for Power Generation Technologies," National Renewable Energiy Laboratory, no. February, 2012, pp. 1-106.

[26] Anonymous, "Environmental Costs of Electricity Generation," Environment Waikato Technical Series, 2007.

\section{Authors' information}

${ }^{1}$ Dept. of Electrical and Information Technology, Universitas Gadjah Mada, Yogyakarta, Indonesia.

Dept. of Electrical Engineering, Universitas Muhammadiyah Yogyakarta, Indonesia.

${ }^{2,3}$ Dept. of Electrical and Information Technology, Universitas Gadjah Mada, Yogyakarta, Indonesia.

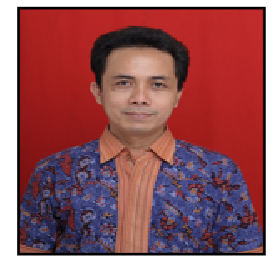

Rahmat A. Al Hasibi was born in Cilacap City, Central Java Province, Indonesia. Currently, he is finishing a doctoral degree at Universitas Gadjah Mada, Yogyakarta, Indonesia. He received a Master degree from the same university in 2012. Both the Master and Doctoral degree major in electrical power system expansion planning and operation.

Since 2005, he has been a faculty member of the Dept of Electrical Engineering at Universitas Muhammadiyah Yogakarta, Indonesia.

Mr. Al Hasibi is a member of the Institute of Electrical and Electronics Engineers with the Power and Energy society. He is also a member of the Indonesian Institute of Professional Engineers.

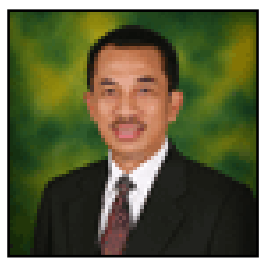

Sasongko Pramono Hadi is lecturer in The Department of Electrical Engineering and Information Technology, Faculty of Engineering, Gadjah Mada University, Yogyakarta, Indonesia. He was born in Klaten, December 27, 1953. In 1979, he received Bachelor degree in Electrical Engineering, Gadjah Mada University, Yogyakarta, Indonesia. He obtained Master andDoctoral degree in 1985 and 1988 respectively, in Electrical Engineering, with research subject: Power System Adaptive Control, from The Institute Nationale Polytechnique de Grenoble (INPG), France.

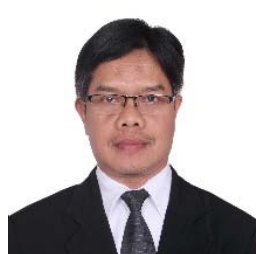

Sarjiya received B.Eng and M.Eng degree in electrical engineering from Universitas Gadjah Mada in 1998 and 2001 respectively. In 2008, he received Ph.D degree from Chulalongkorn University, Thailand. $\mathrm{He}$ is currently an associate professor and chair of department at Department of Electrical and Information Engineering, Universitas Gadjah Mada. His interest includes power systems operation and planning, integration of renewable energy in electric power grid, hybrid renewable energy system and application of optimization in power engineering. 